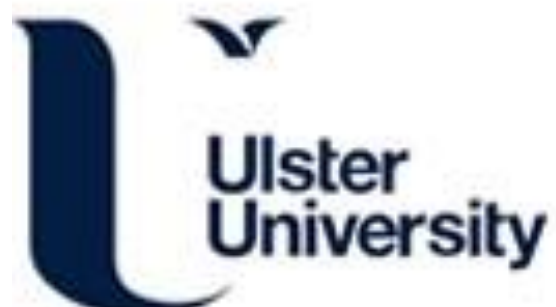

Microneedle drug delivery systems: Appraising opportunities for improving safety and assessing areas of concern

Chege, M., McConville, A., \& Davis, J. (2017). Microneedle drug delivery systems: Appraising opportunities for improving safety and assessing areas of concern. Journal of Chemical Health and Safety, 24(2), 6-14. https://doi.org/10.1016/j.jchas.2016.04.008

Link to publication record in Ulster University Research Portal

Published in:

Journal of Chemical Health and Safety

Publication Status:

Published (in print/issue): 01/03/2017

DOI:

10.1016/j.jchas.2016.04.008

Document Version

Author Accepted version

\section{General rights}

Copyright for the publications made accessible via Ulster University's Research Portal is retained by the author(s) and / or other copyright owners and it is a condition of accessing these publications that users recognise and abide by the legal requirements associated with these rights.

\section{Take down policy}

The Research Portal is Ulster University's institutional repository that provides access to Ulster's research outputs. Every effort has been made to ensure that content in the Research Portal does not infringe any person's rights, or applicable UK laws. If you discover content in the Research Portal that you believe breaches copyright or violates any law, please contact pure-support@ulster.ac.uk. 


\title{
Microneedle Drug Delivery Systems: Appraising Opportunities for Improving Safety and Assessing Areas of Concern
}

\author{
Martha Chege, Aaron McConville and James Davis ${ }^{1}$ \\ School of Engineering, Ulster University, Jordanstown, Northern Ireland, BT37 OQB
}

\begin{abstract}
Transdermal microneedles are regularly advocated as a much safer alternative to conventional hypodermic injections and an ever increasing range of systems are being developed. While there are clear advantages to their adoption, there are a number of safety issues that are emerging which have short and long term implications for patients, clinicians, healthcare administrators and regulators. A brief overview of microneedle design is presented and considered in a critical light in comparison to conventional drug delivery routes. The focus is not on drug safety but rather on the safety concerns of the actual delivery processes for patient and healthcare practitioner. The safety benefits that these new approaches offer and the potential safety concerns that still need to be addressed are highlighted and the possible implications critically assessed.
\end{abstract}

\section{Keywords}

Microneedle; Transdermal Patch; Smart Patches, Needlestick; Dermatitis; Drug Delivery

\footnotetext{
${ }^{1}$ To whom correspondence should be addressed. T: +44(0)2890366407; E: james.davis@ulster.ac.uk
} 


\title{
Microneedle Drug Delivery Systems: Appraising Opportunities for Improving Safety and Assessing Areas of Concern
}

\author{
Martha Chege, Aaron McConville and James Davis ${ }^{1}$ \\ School of Engineering, Ulster University, Jordanstown, Northern Ireland, BT37 OQB
}

\begin{abstract}
Transdermal microneedles are regularly advocated as a much safer alternative to conventional hypodermic injections and an ever increasing range of systems are being developed. While there are clear advantages to their adoption, there are a number of safety issues that are emerging which have short and long term implications for patients, clinicians, healthcare administrators and regulators. A brief overview of microneedle design is presented and considered in a critical light in comparison to conventional drug delivery routes. The focus is not on drug safety but rather on the safety concerns of the actual delivery processes for patient and healthcare practitioner. The safety benefits that these new approaches offer and the potential safety concerns that still need to be addressed are highlighted and the possible implications critically assessed.
\end{abstract}

\section{Keywords}

Microneedle; Transdermal Patch; Smart Patches, Needlestick; Dermatitis; Drug Delivery

\footnotetext{
${ }^{1}$ To whom correspondence should be addressed. T: +44(0)2890366407; E: james.davis@ulster.ac.uk
} 


\subsection{Introduction}

The requirement to provide effective methods of drug delivery whilst minimising risk to patients (and clinicians) is an age old challenge and there is little doubt that the field has improved dramatically in the modern era. It is not, however, free from issues and there remain considerable concerns that relate to the possible adverse effects that can be experienced by the patient should the delivery mechanism fail. Leaving aside the direct toxicological properties of the drug itself, and its possible adverse effects, there are a multitude of chemical and biological safety concerns relating to the actual delivery process that pose considerable technological and procedural challenges to healthcare providers $^{[1-3]}$. The use of injection (subcutaneous, intramuscular or intravenous) is one of the most common approaches to drug administration but it is also a method which has a long history of issues that relate to chemical and biological safety ${ }^{[2,3]}$. As a consequence, there has been a substantial effort to develop new microneedle methods of drug delivery which avoid many of the safety issues presently associated with conventional routes.

Over the past decade, the use of transdermal patches and microneedles has garnered considerable interest and these have begun to reach levels of sophistication where so called "smart patches" are being designed to offer controlled, personalised, dosage profiles ${ }^{[4-8]}$. The level of interest in the development of these new, transdermal systems is emphasized by recent market estimates valuing the current sector at $\$ 31.5 \mathrm{bn}$ with around $12 \%$ of the global drug delivery market being dedicated to transdermal formulations ${ }^{[9]}$. Moreover, there are some 700 clinical trials relating to transdermal delivery registered by the National Institutes of Health $(\mathrm{NIH})^{[10]}$. It must be acknowledged that such figures constitute a wide spectrum of transdermal drug delivery routes - from topical gels to more elaborate microelectromechanical devices. Despite such advances, there are many questions as to whether such systems will provide answers to the issues of safety or whether they may, in fact, present some new ones.

While conventional parenteral drug administration mechanisms are primarily mechanical in nature, the transdermal routes are more reliant on chemical transformations and, as such, raise a number of inherent safety concerns. This report does not consider the detailed chemistries and pharmaco-kinetic efficacy of the release systems, rather, the aim is to provide an overview 
of the new smart microneedle based patch technologies, highlight the possible factors that can give rise to issues over chemical safety and critically assess their ability to provide a truly safer approach to drug delivery.

\subsection{Conventional Delivery - Issues and Practicalities}

Oral administration forms the most common route of administration with the ease of use, lack of invasiveness and the possibility of self-administration accounting for its popularity within the healthcare industries. The delivery process is straightforward and, while the drug itself may possess aggressive properties such as gastrointestinal inflammation or tissue/organ toxicity at high doses, the binder/encapsulant used to deliver the drugs themselves are relatively benign. The approach is not suitable for all drugs however, with the tendency for a drug's performance to become degraded by the effects of hepatic first-pass metabolism which often requires higher dosage with the consequent exacerbation of side effects ${ }^{[4-6]}$. There are also issues with patient compliance where the need for repeat dosing can lead to variations in dose administration which will inevitably lead to undesirable spikes and troughs in the concentration of the drug within the systemic circulation ${ }^{[11,12]}$. Missed or erroneous multiple dosing, caused either by accidental forgetfulness or by conditions such as dementia or Alzheimer's ${ }^{[13,14]}$, is an increasing safety concern and there has been a raft of ancillary products designed to aid adherence to dosing regimes - from simple pill boxes to smart phone apps ${ }^{[15,16]}$.

Hypodermic injections comprise the second most common approach to drug delivery however, like oral administration, it is not without some inherent issues. The associated pain and fear of injection (needle phobia) can significantly impact on patient compliance ${ }^{[6,17]}$. A much more serious limitation relates to unsafe injection practices where, it has been estimated, there are approximately 874 million cases worldwide per annum. There can be a perception that unsafe injection practices frequently stem from the developing world and, in some cases, the re-use of unsterilized equipment within the latter can be commonplace ${ }^{[18]}$ but, it is important to recognise that it is an issue that persists in first world countries ${ }^{[19-25]}$. Improper usage and unsafe administration is linked, but not limited to, the reuse of needles with the consequent spread of infection or disease. Needlestick injuries are a constant hazard irrespective of clinical expertise and the safe disposable of sharps and associated waste can be problematic ${ }^{[20,22,23]}$. It has been 
estimated by the World Health Organisation that of the 35 million global health-care workers, 2 million experience percutaneous exposure to infectious diseases (Hepatitis B (37.6\%), Hepatitis C (39\%) and HIV(4.4\%)) each year ${ }^{[23]}$.

Leaving the potential for blood borne virus and infection aside, the apparently simple process of injection practice can also contribute to safety concerns and the reuse of insulin needles is a particularly contentious example. Repeated needle reuse is relatively common within the diabetic population but there are worries from manufacturers and clinicians alike that it can lead to deformation of the needle tip which increases tissue scarring (lipodystrophy) and can increase the risk of metallic fracture and fragments being left in the skin ${ }^{[26,27]}$.

\subsection{Transdermal Delivery}

The main advantage of hypodermic needle delivery is the ability to avoid gastrointestinal degradation and first pass metabolism which would otherwise reduce the therapeutic yield but there are alternatives. The first transdermal patch delivery system, for the anti-sickness drug scopolamine, gained regulatory approval in 1979 and heralded a significant advancement in non-invasive drug delivery ${ }^{[12]}$. Since its introduction there has been a steady commercialisation of transdermal patches as (indicated in Table 1 within the supporting Information). It is now possible to obtain a number of preparations as an over the counter (OTC) product with nicotine patches arguably being among the most common. In the majority of cases, the delivery process is achieved through passive diffusion across the skin but, while the latter presents a highly accessible and relatively vast surface area, its barrier properties have presented significant hurdles to the passive transport of drugs to systemic circulation ${ }^{[4-6]}$. This partly explains the relatively small number of products available when compared to those delivered through conventional routes. The basic schematic of a conventional transdermal patch found in pharmacies is highlighted in Figure 1. Potential transdermal drug candidates must possess a sufficiently low molecular weight (less than $500 \mathrm{Da}$ ) along with both adequate hydrophilic and lipophilic properties (Log $\mathrm{P}_{\text {(octanol / water partition coefficient) }}$ of 3-5) to enable penetration through the stratum corneum and subsequent epidermal layers ${ }^{[28]}$. 
In order to overcome such limitations, the patch systems have begun to evolve from exploiting simple passive delivery methods, through to more aggressive means of disrupting the structure of the epidermis to increase porosity. The use of chemical enhancers, heat, electroporation, iontophoresis, ultrasound, thermal ablation, and dermabrasion methods have, and continue to be, investigated as routes through which to disrupt the epidermal layers and allow the passage of larger molecules ${ }^{[4-8]}$. There are obvious safety issues associated with the implementation of such methods - the possibility of irritant dermatitis arising from the use of chemical enhancers is an obvious concern ${ }^{[29]}$. The use of cavitational ultrasound and thermal ablation methods also carry concerns over tissue damage ${ }^{[30]}$. In any event, the majority of these systems are largely restricted to clinical research environments and their translation to commercial mainstream products that can be readily administered to patients is severly restricted by the complexity and cost of their implementation. In many respects, such methods have been largely overshadowed in recent years with an ever growing interest in the use of microneedle designs ${ }^{[7-8]}$. This has spurned a large number of different design and material approaches and it is upon these, and their chemical safety implications, that the authors wish to train a spotlight.

\subsection{Microneedles}

The concept of using microneedles as a delivery system stems from 1976 and was viewed as a means of combining the benefits of transdermal and hypodermic methods in a way that would be much more efficient than the former whilst being acceptable to the patient ${ }^{[31]}$. In recent studies investigating user perceptions and experience of microneedles, it was notable that the majority of respondents described the application of the latter as 'pressing,' or 'heavy' in comparison to the 'sharp' and 'stabbing' feeling experienced with conventional hypodermic injections $^{[31]}$. In principle, it could be anticipated that, through physically puncturing the stratum corneum, the range of drugs capable of being delivered through passive patch technologies could be dramatically expanded. The latter are severely restricted as a consequence of the molecular weight and lipophilic requirements necessary to enable passive but, in creating microchannles that bypass the hydrophobic skin barrier, larger, hydrophilic molecules could be readily transferred direct to the microcirculation. The challenge at present relates principally to the delivery of large polypeptides or nucleic acids which would otherwise fail to traverse the SC using traditional transdermal methods ${ }^{[7,8]}$. 
Since their inception, there have been a multitude of design geometries married to an ever increasing range of materials ${ }^{[32,33]}$ but, irrespective of design and fabrication method, they all consist of a base plate upon which a field of micron sized projections (50-900 $\mu \mathrm{m})$ are arranged [33]. Breaching the SC layer simply through "thumb pressure" administration of the patch to the skin stands in marked contrast to the instrumentational complexity and costs inherent to the dermal poration methods mentioned previously. Moreover, the needles are sufficiently short to avoid triggering dermal nerves with recent studies, comparing the skin sensation of applying a flat baseplate with that of a microneedle patch, finding that only $20 \%$ of volunteers could distinguish between the two ${ }^{[34]}$.

Five basic approaches to the design of microneedle drug delivery systems have evolved over the past decades and are based on: solid, coated, hollow, dissolvable and swellable formulations. Their modes of operation are summarised in Figure 2 and their features and safety issues described briefly in the following subsections.

\subsection{Solid Microneedles}

Historically, solid microneedles were the first to emerge and their implementation as a drug delivery route is commonly referred to as a "poke and patch" approach. Microneedles based on silicon, stainless steel or titanium are applied to the skin (as a discrete patch, punch or roller) and are responsible for physically creating micron sized channels in the SC ${ }^{[35-38]}$. Under non occlusive conditions, the barrier function of the SC is typically restored within 2 hours of the original treatment ${ }^{[39,40]}$ but the pore lifetime can be extended through chemical manipulation: diclofenac and fluvastatin have been shown to delay closure by 7 days when used as a co-eluting drug ${ }^{[41,42]}$. The subsequent application of a drug formulation (gel, cream, swab or spray) to the micropunched site allows the therapeutic agent to access the pores and transfer to the underlying microcirculation relatively unimpeded. The two step process is however procedurally cumbersome and the topical delivery of the drug through manual manipulation can be inefficient and economically wasteful when considering high value vaccines or gene therapies ${ }^{[43,}$ 44]. 


\subsection{Coated Microneedles}

The development of solid microneedles coated with the therapeutic agent was an attempt to push earlier approaches towards a single application system that would be much more suitable for patient use. In this case, the drug is coated directly onto the needles using conventional dip or spray coating procedures relying largely on physico-chemical adsorption and avoids any complicated chemical manipulation or surface modifications ${ }^{[45-48]}$. Upon breaching the SC layer the drug molecules simply dissolve into the surrounding tissue and diffuse to the microcirculation. Although offering a one-step procedure, the dosage will depend on the active microneedle area onto which the drug can be coated and, as such, the total yield can be considerably limited and restricted to drugs with a low yield-high potency profile (ie. antigenic material / RNA) ${ }^{[49,50]}$.

It is little surprise therefore to find that the use of coated microneedles has found a particular niche in the delivery of vaccines ${ }^{[51-61]}$. The presence of a significant population of antigen presenting cells (APCs) within the outer skin layers enables a strong immune response to be obtained from the delivery of small amounts of immunogenic material ${ }^{[62]}$ resulting in comparable or superior performance to conventional subcutaneous and intramuscular injections ${ }^{[57-59]}$. Critically, the approach assuages many of the safety concerns associated with needles and avoids issues of patient phobia - especially when considering the vaccination of children ${ }^{[63]}$. This is supported by recent studies where the availability of a self-administered microneedle patch was found to increase the intent to be vaccinated from 44 to $65 \%$ when compared with the standard injection modes ${ }^{[64]}$.

One potentially critical advantage of the microneedle approach towards vaccinations relates to long term storage. The latter has been, and continues to be, a considerable problem with the cold storage requirements necessary to preserve the antigen often hindering decentralised vaccination - particularly in remote locations ${ }^{[65]}$. Many of the approaches taken with the microneedle system employ dry formulations which help overcome the refrigeration limitations. 
Studies by Kommareddy et al. (2013) demonstrated that microneedles coated with the influenza subunit vaccine and stored at room temperature in a desiccated environment remained viable for 8 weeks ${ }^{[57]}$.

\subsection{Hollow Microneedles}

Hollow microneedles (HMN) were principally intended to overcome the dosage limitations inherent to coated solid systems whereby the design mimics that of a conventional hypodermic syringe - albeit on a greatly smaller scale ${ }^{[62,67-70]}$. The HMN are used in conjunction with a drug reservoir typically allowing up to $200 \mu \mathrm{L}$ of therapeutic agent to be released ${ }^{[69]}$. The fabrication processes are significantly more complex and it must also be noted that the move towards hollow needles with a high aspect ratio can also impair the mechanical properties of the structure leading to failure if improperly inserted (discussed in later sections). The situation can be further compounded by blockage of the needle bore with dermal tissue during the insertion process resulting in a much reduced release efficiency ${ }^{[70]}$.

\subsection{Dissolvable Polymer Microneedles}

Dissolvable microneedles are a much more recent development and typically involve the incorporation of the drug within the polymer framework used to form the needle structure ${ }^{[71-}$ ${ }^{76]}$. The dissolution of the polymer releases the entrapped drug and an example is highlighted in Figure 3. The main limitation however is that the delivery yield can be overly restrictive and it is important to appreciate that the primary drug delivery component is the needle structure and not the supporting base plate ${ }^{[33]}$. This necessitates that a compromise is reached between drug yield and the amount of polymer necessary to ensure the mechanical integrity of the needle structure. The larger the size of the drug - the lower the concentration which can be reliably delivered. A secondary concern relates to the processing requirements for the formation of the microneedle and compatibility with the therapeutic agent. High temperatures, solvents, extreme $\mathrm{pH}$ profiles can significantly affect the viability of protein and vaccine based drugs. 


\subsection{Swellable Microneedles}

These are typically based on a hydrophilic hydrogel framework which absorbs fluid from the surrounding tissue and physically swells creating pores/nanochannels within the needle through which the drug can diffuse ${ }^{[43]}$. In contrast to the dissolvable $\mathrm{MN}$ system, drug molecules contained within the baseplate can be efficiently transferred through the needle to the surrounding tissue. The rate at which transfer occurs can be finely tuned through manipulating the number of crosslinks within the hydrogel structure.

\subsection{Microneedle Safety: Features and Concerns}

The stratum corneum's prime role is to serve as an efficient barrier regulating water loss and preventing the ingress of contaminants and therefore any material that physically breaches the wall to allow material to pass, relatively unhindered, to the microcirculation and beyond will inevitably raise concerns. Much of the initial safety evaluation and patient assessments have been conducted in relation to solid microneedle systems and there are many favourable aspects to their implementation when compared with conventional injection systems. It has been shown that for solid microneedle systems, the channels are closed within a few hours of the original injury and that normal skin function is restored with typically no sustained erythema following their removal ${ }^{[39,40]}$. The use of silicon, stainless steel and titanium are relatively benign from a biocompatibility perspective and there are few issues in relation to irritant contact dermatitis [39].

One particular concern has been the fact that microchannels can create a highway through which bacteria can gain access to the underlying tissues however, in general, the possibility of infection can be greatly minimised by good clinical practice. The application of antibacterial wipes (alcoholic chlorhexidine etc.) prior to exposure is a standard procedure and can preclude the influx of adventitious species present within the surrounding skin. It must also be noted that there have been a number of studies that have shown that the potential for infection after microneedle exposure is markedly less than that with conventional injection methods ${ }^{[77,78]}$. The 
use of polymer microneedles brings some unique properties that can further minimise the possibility of infection. There is an increasing interest in the use of polymers possessing an inherent antibacterial action (i.e. those with quaternary nitrogen atoms/heterocyclic structures) to provide the needle framework within which the drug is either coated or encased and thereby acts to actively counter any microbes that have been accidently drawn into to the channels as a consequence of the application procedure or their subsequent influx ${ }^{[79]}$.

The US Needlestick Safety and Prevention Act (2000) requires that sufficient training in the use of safe procedures and appropriate personal protective equipment is provided and devices for rendering contaminated sharps into a safe form after use (ie needle encapsulation covers/attachments) are readily available ${ }^{24}$. Despite such provisions, the prevalence of such injuries are an ever present concern within hospital and community healthcare. A survey by the American Nursing Association into the causes and frequency of needlestick events found that most occur during injection (28\%), before applying the safety enclosure (19\%) or during disposal of the needle (19\%). It was also reported that $64 \%$ of the respondents reported being accidently struck by a needle ${ }^{[20]}$. Bilateral injuries are a significant cause of needlestick and arise predominantly as a consequence of applying the normally prescribed method of a skin "pinch" whereby a raised fold of skin is created between the thumb and forefinger of the non dominant hand prior to the administration of a subcutaneous injection ${ }^{[21]}$. Such practices run the risk of the needle travelling through the skin fold into the finger of the healthcare worker with the subsequent withdrawal of the needle resulting in the potential exposure of each to the blood of the other. It has been estimated that the latter accounts for 1 in 30 injection injuries ${ }^{[21]}$.

It could be envisaged that there remains a potential hazard for needlestick injuries to occur with the microneedle patches through the careless handling of the patch pre and post application and this would certainly be a cause for concern where solid ( $\mathrm{Si}$, Steel or Ti) needles are employed. The lack of sensation associated with their application could be particularly dangerous where accidental puncture occurs as there will be little in the way of warning to the healthcare worker that a potential needlstick injury has occurred. The use of dissolvable microneedles however, presents a truly innovative solution which greatly reduces the risk of post needlestick injury. In this case, the micro projections that constitutes the "sharp" hazard are effectively destroyed in the process of delivering the drug/vaccine ${ }^{[1-3]}$. It could also be 
envisaged that swellable needle systems will also markedly reduce post stick injuries as the hydrated form will have lost much of the mechanical rigidity necessary for skin puncture. This automatic self-disabling mechanism is a critical safety feature as it is found that some $6 \%$ of needlestick injuries arising from hypodermic injection arise from attempts to engage the safety enclosure $^{[20]}$.

Most countries will have legislation in place to mandate the safe disposal of hypodermic syringes and associated sharps but there is little doubt that the volume of waste associated with conventional devices creates an economic burden for healthcare administrators. One example of the magnitude is given by Emmanuel and colleagues (2004) in which it was reported that a relatively small vaccination campaign in the Philippines gave rise to over 130 tonnes of sharps waste ${ }^{[80]}$. Clearly, the small size of the microneedle patches would dramatically counter such volumes. Moreover, the dissolution of the "sharp" component in the case of dissolvable and swellable polymer formats would undoubtedly ease the post use disposal processing.

One of the core selling points in relation to microneedles, irrespective of design, is the ease with which they can be applied. While it is true that the near invisible nature of the needle array can instantly remove apprehension, there are concerns over the possibility of ineffectual application and administration ${ }^{[81,82]}$. Microneedles can be self-administered through "thumb pressure" or a "snap" applicator but there can be little indication that the needles have indeed pierced the SC. Recent investigations have shown that thumb pressure application is successful in almost $90 \%$ of cases, nevertheless there was often a need for multiple attempts and instruction to increase the success rate ${ }^{[81,82]}$. It must be acknowledged that microneedles intended for skin puncture will be subject to a wide range of mechanical stresses. Variations in skin morphology can lead to non-uniform insertion of the microneedle array and can induce sheer stresses and transverse bending of the microneedles ${ }^{[83,84]}$. Random movements during the manipulation of the patch assembly during insertion and removal, especially where there are multiple attempts, will inevitably result in axial compression and sheer stresses which may lead to the failure and fracture of the needles ${ }^{\left[{ }^{85-88]}\right.}$. It is also important to note that the baseplate which forms the foundation of the patch can also be subject of bending forces which, if not sufficiently flexible, can fracture ${ }^{[89]}$. It has been shown that a decrease in the microneedle height provides a more favourable safety margin ${ }^{[83]}$. 
The relatively painless application is clearly an advantage but it can also be a limitation where there is uncertainty over whether not the microneedles have been successful in delivering their load. There is a need for some form of feedback mechanism to alert the patient (or clinician) that the microneedle has successfully deployed and that the needles have penetrated to the correct depth ${ }^{[81,82]}$. Such issues are of paramount importance in the case of vaccine delivery where there is an ever increasing interest in the use of microneedles and the consequences of a false positive could be life threatening. At present, many of the preliminary investigations utilise dyes (typically methylene blue ${ }^{[90,91]}$ or trypan blue ${ }^{[92,93]}$ ) as model drugs where delivery to the skin and the subsequent puncture can be easily visualised by the transfer. Moreover, they are known to selectively stain living cells within the epidermis and not simply the top most layers of the $\mathrm{SC}$ and can be used as gauge for the creation of microchannels ${ }^{[88]}$. It could be anticipated that the inclusion of an inert (biodegradable) dye within the actual drug loaded patch could go some way to providing an immediate feedback indication for successful delivery.

It has been noted that the time from puncture to recovery in terms of solid microneedle is of the order of several hours but there is little information on the closure profile where polymer fragments are left to transcend the skin barrier. The fast healing of the microchannels are a major factor in minimising the possibility of infection but the failed removal of a swellable microneedle may end up serving as a longer lived conduit to the underlying tissue. At present there is a dearth of studies that can consider the mechanical failure of such systems and the consequences for restoring skin integrity.

The increasing interest in the use of polymer microneedles in the form of dissolvable and swellable structures have, as indicated, many advantageous features but there is an assumption that their structure is wholly removed - either by dissolution or mechanical retrieval of the patch.

The main cause for concern arises where there is incomplete dissolution or metabolism of the polymer constituents such that deposits are left within the skin ${ }^{[94]}$. It could also be theorized that the physical transformations that accompany swellable systems will necessarily weaken their attachment to the base plate of the plate and increase the possibility of fragmentation when removal is attempted. Given the latter are not designed for complete dissolution then this 
could exacerbate irritation and stimulate the rich immune cell population of the skin ${ }^{[94,95]}$. In either case, it has been postulated that where there is repeated application of the patch (ie for insulin delivery), there is a possibility of polymer fragments being distributed and deposited throughout the skin which could be mobilised and result in hepatic accumulation ${ }^{[94,95]}$. As such, it could be expected that in some cases, the single use application of the patch is advised.

\subsection{Conclusions}

Most patients will display at least a degree of apprehension when faced with the need for a hypodermic injection but most will be unaware of the many safety issues that surround the handling, application and subsequent disposal of the syringe. Microneedles have evolved as a possible alternative which have been proven to dispel many of the patient's concerns but there remain some issues over their use. Microneedles clearly have many advantages over conventional systems but they cannot be viewed as a total replacement as their dosage capacity is, by virtue of their design, considerably limited. As such, they are generally restricted to low yield high potency applications and have found ideal niche as vaccine delivery systems. The latter is particularly pertinent given the near universal reluctance of children to wilfully undergo injection, and it has been demonstrated that the more benign perception of the needle patch can actually enhance participation.

While it is clear that microneedles hold considerable promise and commercial systems have begun to arise, the research effort that underpins the development processes can be lacking in a full appraisal of their safety. It is all too common to find research literature extolling the material benefits of a new microneedle design but with minimal appreciation of the need to clarify the failure stresses that can occur and the possible consequence of fracture fragmentation of the needle. Many of the failure stresses are conducted using conventional mechanical testing models rather than accurately simulating insertion within a more fluid epidermal layer and yet this is a crucial factor in ensuring safe administration and removal of the microneedle patch . Dissolvable needle systems are becoming more apparent and the self-disabling mechanism is a highly innovative approach to needlestick safety but there are still many questions as to the toxicological aspects of polymer residues being left in the skin and the consequence of polymer 
fragments leaving the skin open to potential infection. Confirmation of successful delivery is often overlooked yet it is a critical requirement and the need for a simple feedback system is presently lacking.

\section{Acknowledgements}

The authors thank the Department of Employment and Learning (DEL) Northern Ireland for supporting this research.

\section{Supporting Information}

Detailed tables containing comprehensive lists of the different type of commercial transdermal patches and polymers used in the construction of microneedle patch systems along with the drug/vaccine load is available.

\section{References}

1. Sastry S, Nyshadham J. Pharm Sci Technolo Today 2000;3(4):138

2. Simonsen L, Kane A, Lloyd J. Bull World Health Organ 1999;77(10):789

3. Wright S, Yelland M, Heathcote K. Aust Fam Physician 2009;38(3):172

4. Ruby PK, Pathak SM, and Aggarwal D. Drug Dev Ind Pharm, 2014; 40(11): 1421

5. Cevc G, Vierl U. J Control Release 2010; 141 (3):277.

6. Bariya SH, Gohel MC, Mehta TA, Sharma OP. J Pharm Pharmacol 2012;64(1):11

7. Quinn HL, Kearney M-C, Courtenay AJ, McCrudden MTC, Donnelly RF. Expert Opinion on Drug Delivery, 2014; 11: 1769

8. Rejinold NS, Shin J-H, Seok HY, Kim YC. Expert Opinion on Drug Delivery, 2016; 13:1, 109

9. Allen D. Pharmaceutical \& Medical Packaging News. 2011

10. ClinicalTrials.gov. Home. 2015

11. Prausnitz MR, Langer R. Nat Biotechnol 2008; 26 (11):1261

12. Subedi RK, Oh SY, Chun M-K, Choi H-K. Arch Pharm Res 2010;33(3):339

13. Molinuevo JL, Arranz FJ. Expert Rev Neurother 2012;12(1):31 
14. Chiatti C, Bustacchini S, Furneri G, Mantovani L, Cristiani M, Misuraca C. Drug Saf 2012; 35 Suppl 1:73

15. Morales Suárez-Varela MT. Aten Primaria 200941 (4), 185

16. Lindsey Dayer, Seth Heldenbrand, Paul Anderson, Paul O. Gubbins and Bradley C. J AM Pharm Assoc (2003). 53 (2), 172

17. Sokolowski CJ, Giovannitti JA, Boynes SG. Dent Clin North Am 2010;54(4):731

18. Pépin J, Abou Chakra CN, Pépin E, Nault V. PLoS One 2013;8(12):e80948.

19. Pugliese G, Gosnell C, Bartley JM, Robinson S, American Journal of Infection Control 2010; 38(10) 789

20. American Nurses Association, 2008 Study of Nurses' Views on Workplace Safety and Needlestick Injuries, 2008

21. Black L, American Journal of Infection Control 2013; 41: 815

22. European Agency for Safety and Health at Work. Risk assessment and needlestick injuries, 2008, pp 1-8

23. World Health Organisation (WHO) The world health report, 'Chapter 4 - Selected occupational risks', 2002.

24. Needlestick Safety and Prevention Act of 2000, Publication No. 106-430, 114, Stat. 1901; Government Printing Office (November 6, 2000).

25. Jason J, Journal of Public Health 2013; 35(3): 422

26. A Look at the Reuse of Insulin Needles. The Early Days of Needle Reuse. (n.d.). 1998

27. Dia-, N. T. A. (n.d.). ADA Discourages Needle Reuse.

28. Young B C and Mark R. Prausnitz. Pharm Res. 2011 (5), 943

29. Zhai, H \& Maibach, H. I. Contact Dermatitis, 2001, 44(ii), 201

30. Smith B N. Int J Nanomedicine. 20072 (4), 585

31. Pawar RG, Pawar SD, Gadhave MV, Jadhav SL, Gaikwad DD. J of Drug Delivery \& Therapeutics. $20122(1), 76$

32. Olatunji O, Das DBD, Garland MJ. J Pharm Sci 2013;102(4):1209

33. Tuan-Mahmood T-M, McCrudden MTC, Torrisi BM. Eur J Pharm Sci 2013;44(5):623

34. Haq MI, Smith E, John DN. Biomed Microdevices 2009;11(1):35

35. McAllister DV, Wang PM, Davis SP. Proc Natl Acad Sci USA 2003;100(24):13755

36. Zhou CP, Liu YL, Wang HL. Int J Pharm 2010;392(1-2):127

37. Mikolajewska P, Donnelly RF, Garland MJ. Pharm Res 2010;27(10):2213

38. Stahl J, Wohlert M, Kietzmann M. BMC Pharmacol Toxicol 2012;13(1):5

39. Donnelly RF, Mooney K, McCrudden MTC. J Pharm Sci 2014;103(5):1478

40. Gupta J, Gill HS, Andrews SN, Prausnitz MR. J Control Release 2011;154(2):148 
41. Brogden NK, Banks SL, Crofford LJ, Stinchcomb AL. Pharm Res 2013;30(8):1947

42. Ghosh P, Brogden NK, Stinchcomb AL. J Pharm Sci 2014;103(2):652

43. Donnelly RF, Thakur RRS, Garland MJ. Adv Funct Mater 2012;22(23):4879

44. Mark R. Prausnitz, John A. Mikszta, Michel Cormier, and Alexander K. Andrianov. Curr Top Microbiol Immunol. 333, 369

45. Chen J, Qiu Y, Zhang S. Drug Dev Ind Pharm 2013

46. Tas C, Mansoor S, Kalluri H. Int J Pharm 2012;423(2):257

47. Cormier M, Johnson B, Ameri M. J Control Release 2004;97(3):503

48. Daddona PE, Matriano JA, Mandema J, Maa Y-F. Pharm Res 2011;28(1):159

49. Pearton M, Saller V, Coulman SA. J Control Release 2012;160(3):561

50. Chong RHE, Gonzalez-Gonzalez E, Lara MF. J Control Release 2013;166(3):211

51. Matsuo K, Okamoto H, Kawai Y. J Neuroimmunol 2014;266(1-2):1

52. McGrath MG, Vrdoljak A, O'Mahony C. Int J Pharm 2011;415(1-2):140

53. Weldon WC, Zarnitsyn VG, Esser ES. PLoS One 2012;7(7):e41501

54. Choi HJ, Bondy BJ, Yoo DG. J Control Release 2013;166(2):159

55. Chen X, Fernando GJP, Raphael AP. J Control Release 2012;158(1):78

56. Edens C, Collins ML, Ayers J. Vaccine 2013;31(34):3403

57. Kommareddy S, Baudner BC, Bonificio A. Vaccine 2013;31(34):3435

58. Zhu Q, Zarnitsyn VG, Ye L. Proc Natl Acad Sci USA 2009;106(19):7968

59. Wang B-Z, Gill HS, He C. J Control Release 2014;178:1

60. Vrdoljak A, McGrath MG, Carey JB. J Control Release 2012;159(1):34

61. Saade F, Petrovsky N. Expert Rev Vaccines 2012;11(2):189

62. Al-Zahrani S, Zaric M, McCrudden C. Expert Opin Drug Deliv 2012;9(5):541

63. Norman JJ, Brown MR, Raviele NA. Pediatr Diabetes 2013;14(6):459

64. Norman JJ, Arya JM, McClain MA. Vaccine 2014;32(16):1856

65. Lee BY, Cakouros BE, Assi T-M. Vaccine 2012;30(38):5637

66. Zhou C-P, Liu Y-L, Wang H-L. Int J Pharm. 2010; 392:127

67. Wang P-C, Paik S-J, Kim S-H, Allen MG. J Microelectromechanical Syst 2014;1:1

68. Martanto W, Moore J, Kashlan O. Pharm Res 2006;23(1):104

69. Burton SA, Ng CY, Simmers R. Pharm Res 2011;28(1):31

70. Gardeniers HJGE, Luttge R, Berenschot EJW. J Microelectromechanical Syst 2003;12(6):855

71. Garland MJ, Migalska K, Tuan-Mahmood T-M. Int J Pharm 2012;434(1-2):80

72. Gomaa YA, Garland MJM, Mclnnes F. Int J Pharm 2012;82:299

73. Migalska K, Morrow DIJ, Garland MJ. Pharm Res 2011;28(8):1919

74. Ito Y, Murano H, Hamasaki N. Int J Pharm 2011;407(1-2):126 
75. Kim MY, Jung B, Park J-H, Biomaterials 2012; 33:668

76. Lee JW, Choi S-O, Felner EI, Prausnitz MR. Small 2011;7(4):531

77. Donnelly RF, Thakur RRS, Tunney MM. Pharm Res 2009;26(11):2513

78. Li W-Z, Huo M-R, Zhou J-P. Int J Pharm 2010;389(1-2):122

79. Donnelly RF, Thakur RRS, Alkilani AZ. Int J Pharm 2013;451(1-2):76

80. Emmanuel J, Ferrer M, Ferrer F. Waste management and disposal during the Philippine follow-up measles campaign. Health Care Without Harm and The Health Department of The Philippines; 2004.

81. Donnelly RF, Moffatt K, Alkilani AZ. Pharm Res 2014

82. Birchall JC, Clemo R, Anstey A, John DN. Pharm Res 2011;28(1):95

83. Park J-H, Allen MG, Prausnitz MR. J Control Release. 2005;104(1):51

84. Demir YK, Akan Z, Kerimoglu O. PLoS One.2013;8(10):1

85. Khanna P, Luongo K, Strom JA, Bhansali S. J Micromech Microengineering. 2010;20:045011.

86. Khanna P, Silva H, Bhansali S. Procedia Eng. 2010;5:977

87. Zahn J, Talbot N, Liepmann D, Pisano A. Biomed Microdevices. 2000;2(4):295

88. Gittard SD, Chen B, Xu H, Ovsianikov A, Chichkov BN, Monteiro-Riviere NA, J Adhes Sci Technol. 2013;27:227

89. Donnelly RF, Majithiya R, Singh TRR, Morrow DIJ, Garland MJ, Demir YK, Pharm Res. $2011 ; 28(1): 41$

90. Kalluri H, Kolli CS, Banga AK. AAPS J.2011;13(3):473

91. Pearton M, Saller V, Coulman SA, Gateley C, Anstey AV, Zarnitsyn V. J Control Release. $2012 ; 160(3): 56$

92. Gomaa YA, Morrow DIJ, Garland MJ, Donnelly RF, El-Khordagui LK, Meidan VM. Toxicol In Vitro. 2010;24(7):1971

93. Kochhar JS, Quek TC, SoonWJ, Choi J, Zou S, Kang L. skin. J Pharm Sci. 2013;102(11):4100

94. Bal SM, Caussin J, Pavel S, Bouwstra JA. Eur J Pharm Sci 2008;35(3):193

95. Del Pilar M M, Weldon W, Zarnitsyn V. MBio 2012;3(2):e00012 


\section{Figure Legends}

Figure 1. Conventional transdermal patch assembly

Figure 2. Mode of action inherent to solid (A), coated (B), hollow(C), dissolvable(D) and swellable (E) microneedle systems.

Figure 3. SEM image of morphological change in microneedles with hydrogel microparticles regarding contact duration with PBS (a) $0 \mathrm{~s}$, (b) $10 \mathrm{~s}$, (c) $30 \mathrm{~s}$, and (d) $60 \mathrm{~s}$. SEM image of all microneedles broken mechanically after $60 \mathrm{~s}$ of contact (e). Microneedles were made of PLGA and 53\% (v/v) of hydrogel particles were encapsulated in an array of microneedles. Reproduced from (75). 


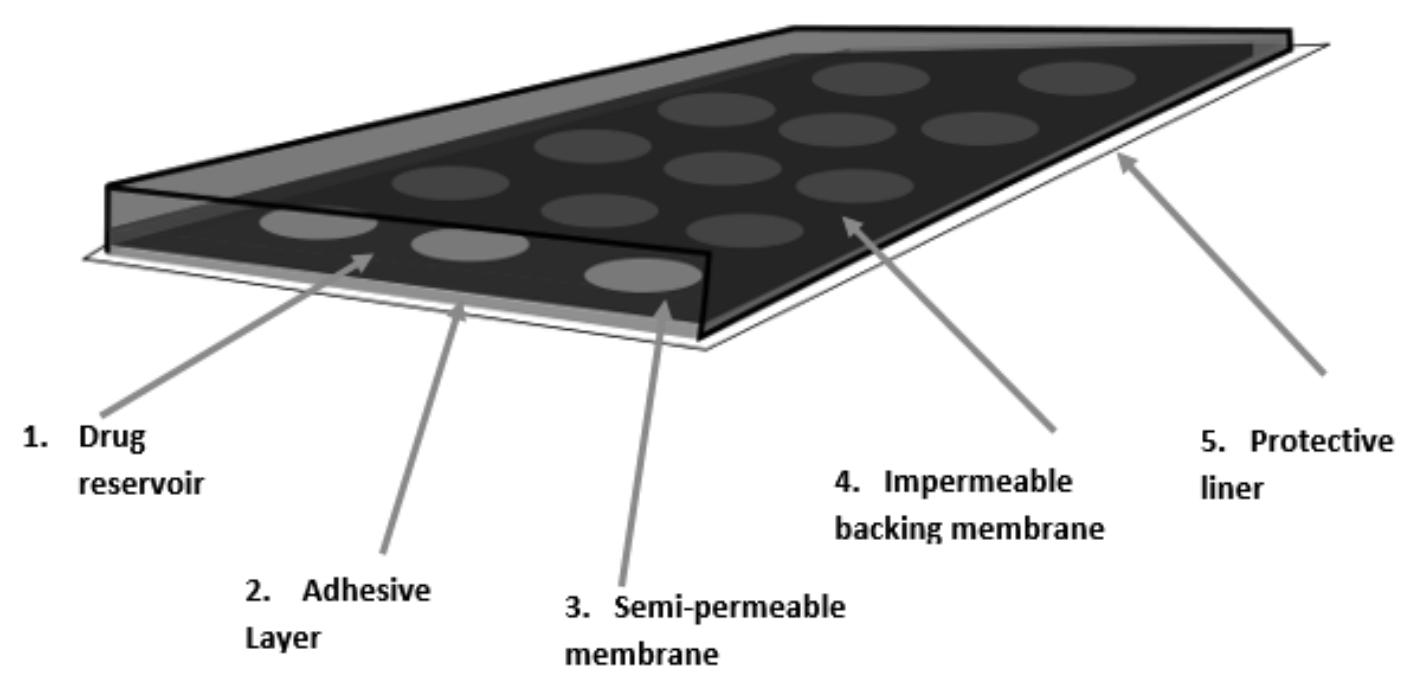

Figure 1. Conventional transdermal patch assembly 


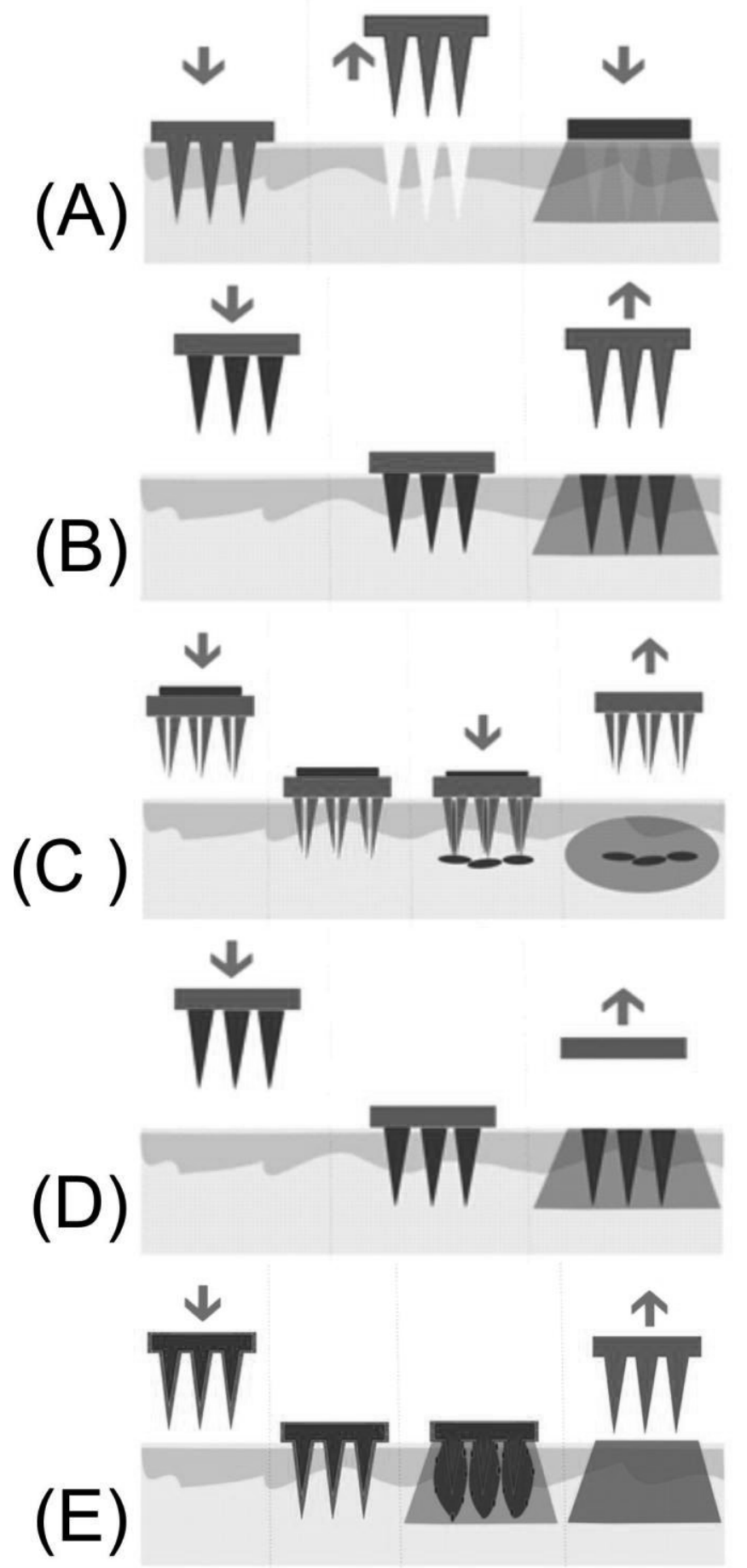

Figure 2. Mode of action inherent to solid (A), coated (B), hollow(C), dissolvable(D) and swellable (E) microneedle systems. 

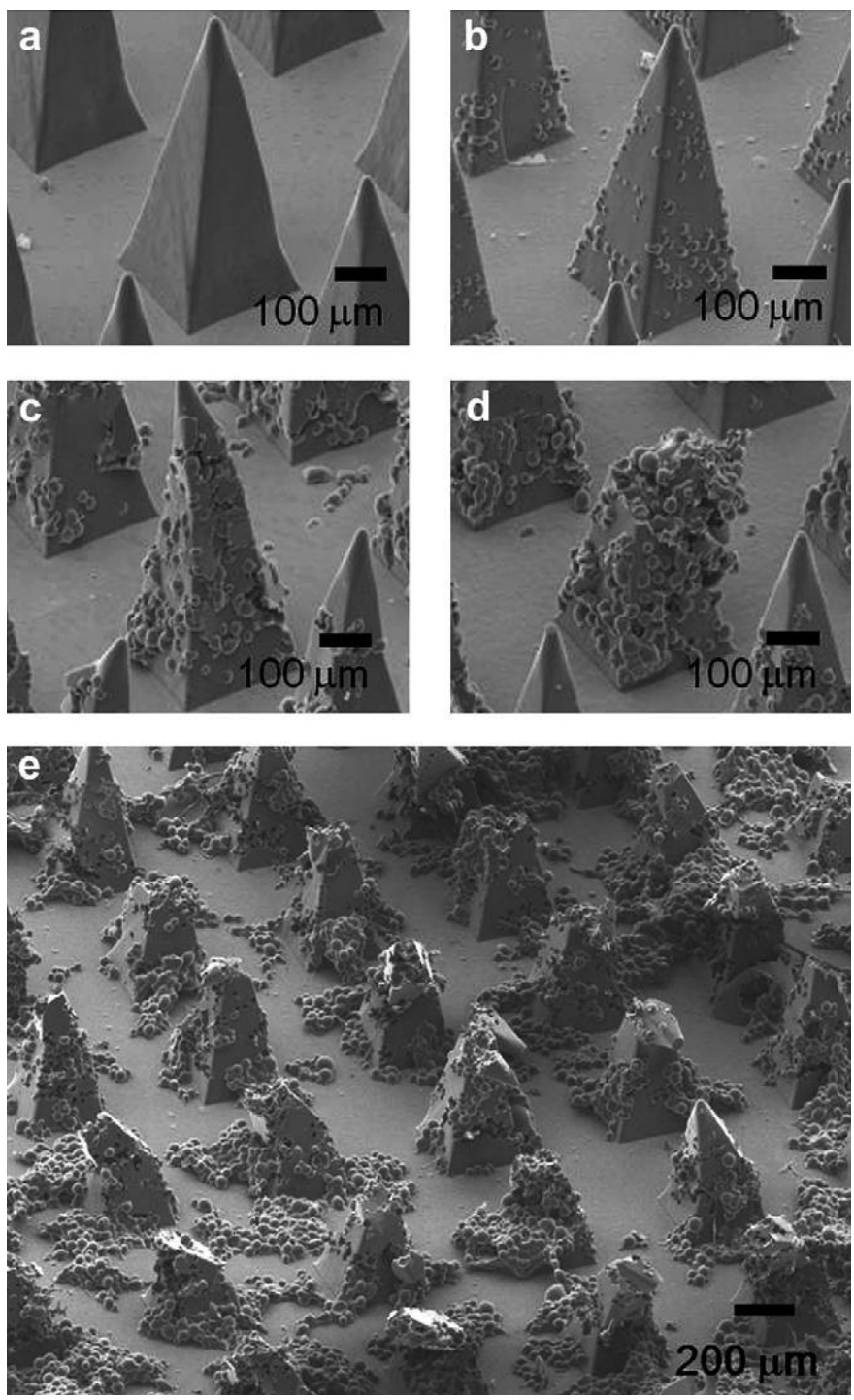

Figure 3. SEM image of morphological change in microneedles with hydrogel microparticles regarding contact duration with PBS (a) $0 \mathrm{~s}$, (b) $10 \mathrm{~s}$, (c) $30 \mathrm{~s}$, and (d) $60 \mathrm{~s}$. SEM image of all microneedles broken mechanically after $60 \mathrm{~s}$ of contact (e). Microneedles were made of PLGA and 53\% (v/v) of hydrogel particles were encapsulated in an array of microneedles. Reproduced from (75). 


\title{
Microneedle Drug Delivery Systems: Appraising Opportunities for Improving Safety and Assessing Areas of Concern
}

Martha Chege, Aaron McConville and James Davis ${ }^{1}$

School of Engineering, Ulster University, Jordanstown, Northern Ireland, BT37 OQB

\begin{abstract}
Transdermal microneedles are regularly advocated as a much safer alternative to conventional hypodermic injections and an ever increasing range of systems are being developed. While there are clear advantages to their adoption, there are a number of safety issues that are emerging which have short and long term implications for patients, clinicians, healthcare administrators and regulators. A brief overview of microneedle design is presented and considered in a critical light in comparison to conventional drug delivery routes. The focus is not on drug safety but rather on the safety concerns of the actual delivery processes for patient and healthcare practitioner. The safety benefits that these new approaches offer and the potential safety concerns that still need to be addressed are highlighted and the possible implications critically assessed.
\end{abstract}

\section{Supporting Information}

Table 1. Commercial Transdermal Patches

Table 2. Microneedle Composition, Design and Delivery

\footnotetext{
${ }^{1}$ To whom correspondence should be addressed. T: +44(0)2890366407; E: james.davis@ulster.ac.uk
} 


\section{Table 1. Commercial Transdermal Patches}

\begin{tabular}{|c|c|c|}
\hline Year & Drug & Application \\
\hline 1979 & Scopolamine & Antisickness \\
\hline 1984 & Clonidine & Hypertension \\
\hline 1986 & Estradiol & Menopause symptoms \\
\hline 1990 & Fentanyl & Acute post-operation pain \\
\hline 1993 & Testosterone & Hypogonadism \\
\hline 1995 & Nitroglycerine & Angina pectoris \\
\hline 1996 & Nicotine & Cigarette smoking cessation \\
\hline 1999 & Lidocaine & Local anaesthetic \\
\hline 2001 & $\begin{array}{l}\text { Enthinyl Estradiol } \\
\text { w/Norelgestromin }\end{array}$ & Contraceptive \\
\hline 2003 & $\begin{array}{l}\text { Estradiol } \\
\text { w/levonorgestrel }\end{array}$ & Menopause symptoms \\
\hline 2003 & Oxybutin & Overactive bladder \\
\hline 2005 & $\begin{array}{l}\text { Lidocaine } \\
\text { w/ tetracaine }\end{array}$ & Local anaesthetic \\
\hline 2006 & Methylphenidate & ADHD \\
\hline 2006 & Selegiline & Depression \\
\hline 2007 & $\begin{array}{l}\text { Diclofenac } \\
\text { Epolamine }\end{array}$ & Anti-inflammatory \\
\hline 2007 & Rivastigmine & Dementia \\
\hline 2007 & Rotigotine & Parkinson's Disease \\
\hline 2008 & Granisteron & Chemotherapy \\
\hline 2013 & $\begin{array}{l}\text { Sumatriptan } \\
\text { Succinate }\end{array}$ & Antimigraine agent \\
\hline 2014 & Oxitriptan & Depression \\
\hline
\end{tabular}

1. Electronic Orange Book. (2016). Approved drug products with therapeutic equivalence evaluations 36th Edition. Available: http://www.fda.gov/default.htm. 
Table 2. Microneedle Composition, Design and Delivery

\begin{tabular}{|c|c|c|c|}
\hline Material & Type & Drug/Vaccine & Ref \\
\hline Silicon & $S$ & $\begin{array}{l}\text { BSA } \\
\text { Insulin } \\
\text { Ovalbumin(OVA) } \\
\text { Rhodamine-labelled dextran } \\
\text { Ethidium bromide } \\
\text { Calcein }\end{array}$ & 1,2 \\
\hline Silicon & $S$ & $\begin{array}{l}\text { Meso-tetra( N-methyl-4- } \\
\text { pyridyl)porphine tetratosylate } \\
\text { Plasmid DNA } \\
\text { Galanthamine }\end{array}$ & 2 \\
\hline Silicon & $S$ & $\begin{array}{l}\text { 5-aminolevulinic acid } \\
\text { 5-aminolevulinic acid methyl ester }\end{array}$ & 3 \\
\hline Silicon & C & $\begin{array}{l}\text { OVA protein vaccine } \\
\text { Human Influenza vaccine } \\
\text { rADV }\end{array}$ & 4 \\
\hline Silicon & $\mathrm{H}$ & $\begin{array}{l}\text { Methyl nicotinate } \\
\text { Hexyl nicotinate } \\
\text { Influenza vaccine }\end{array}$ & 2,5 \\
\hline Mesoporous Silicon & $S$ & $\begin{array}{l}\text { Ibuprofen } \\
\text { Antipyrine Griseofulvin } \\
\text { Ranitidine } \\
\text { Furosemide }\end{array}$ & 6 \\
\hline Metals & & & \\
\hline Stainless Steel & $\mathrm{S}$ & $\begin{array}{l}\text { Naltrexone } \\
\text { Insulin } \\
\text { Diptheria toxoid }\end{array}$ & 2 \\
\hline Stainless Steel & C & $\begin{array}{l}\text { Licodaine } \\
\text { Vitamin B } \\
\text { Calcein } \\
\text { Luciferase } \\
\text { Sulforhodamine } \\
\text { Fluorescein } \\
\text { Curcumin } \\
\text { Cisplatin } \\
\text { Modified Vaccinia virus Ankara } \\
\text { Human IgG } \\
\text { Salmon calcitonin }\end{array}$ & 2,4 \\
\hline Titanium & C & $\begin{array}{l}\text { rhGH } \\
\text { OVA } \\
\text { Desmopressin }\end{array}$ & 4 \\
\hline
\end{tabular}




\section{Biodegradable polymers}

Poly-L-lactic Acid

(PLA)

Polygycolic Acid

(PGA)

Polylactide-co-glycolic Acid (PLGA)

Polyvinylpyrrolidone (PVP)

Polyvinyl alcohol (PVA)

Polycarbonate

Non-biodegradable polymers

Polyvinyl acetate (PVA)

Alginic Acid

Carbopol 971 P-NF

Polycaprolactone

Polysterene-block-Poly acrylic Acid

Poly(methyl vinyl ether-co-maleic anhydride)

Polyethylene gycol (PEG)

Poly[di(carboxylatophenoxy)phosphazene]

Plastic
D

OVA

D Human IgG

C Voriconazole

D Tetanus toxoid

BSA

Calcein

Desmopressin

BSA

Influenza vaccine

D Sulforhodamine B

2

S Calcein

2

2

4

2
2,8

(1)

D Theophylline $\quad 9,10$

$\begin{array}{lll}\text { D BSA } & 9,10\end{array}$

D Theophylline $\quad 9,10$

D Doxorubicin hydrochloride $\quad 11$

SW Anti-scarring agents/antibiotics 12

C Miconazole 4

C Licodaine 4

C Hepatitis B vaccine 10

S Chimeric flavivirus vaccine 2

Anthrax vaccine

Rabies vaccine

Influenza vaccine

\section{Natural polymers}

Thermoplastic starch

Carboxymethylcellulose
D Tetanus toxoid

D Insulin
1,13

8,13 
Sulforhodamine B

Lidocaine $\mathrm{HCl}$

\begin{tabular}{|c|c|c|c|}
\hline Amylopectin & D & Sulforhodamine B & 2 \\
\hline Dextran & D & $\begin{array}{l}\text { LMW Heparin } \\
\text { Erythropoietin } \\
\text { rhGH }\end{array}$ & 2,14 \\
\hline Chondroitin sulphate & D & $\begin{array}{l}\text { LMW Heparin } \\
\text { Erythropoietin } \\
\text { rhGH } \\
\text { Leuprolide acetate }\end{array}$ & 2,14 \\
\hline Galactose & D & $\begin{array}{l}\text { 5-aminolevulinic acid } \\
\text { BSA }\end{array}$ & 2,14 \\
\hline Maltose & $\begin{array}{l}D \\
S \\
S \\
D\end{array}$ & $\begin{array}{l}\text { Human IgG } \\
\text { Nicardipine hydrochloride } \\
\text { Methotraxate } \\
\text { LMW Heparin }\end{array}$ & 14,15 \\
\hline
\end{tabular}

\section{Ceramics}

Aluminium Oxide

Alumina and zirconia
NP

$\begin{array}{ll}H & \text { Vaccines }\end{array}$

H Sulforhodamine B Insulin

Where: $\mathrm{S}=$ solid; $\mathrm{C}$ = coated; $\mathrm{H}=$ hollow; $\mathrm{D}=$ dissolvable; $\mathrm{SW}=$ swellable; $\mathrm{NP}=$ nanoporous; $\mathrm{rADV}=$ recombinant human adenovirus; IgG= human immunoglobulin; $\mathrm{BSA}=$ bovine serum albumin; $\mathrm{LMW}=$ low molecular weight; $\mathrm{rhGH}=$ recombinant human growth hormone.

\section{References}

1. Shital H, Mukesh C. Gohelb, Tejal A. J Pharm and Pharmclgy. 64, 11

2. Garland, Martin J; Migalska, Katarzyna. Expert Rev of Med Devices 8.4 (Jul 2011): 459

3. Li-Wen Z, Yi-Ping Fang, Jia-You Fang. Dermatologica Sinica. 29 (1), 1

4. Haj-Ahmad R, Hashim K, Muhammad S A, Manoochehr R, Amjad, Walsh S, Xiang Li, Ming-Wei C and Zeeshan A. Pharmaceutics 20157 (4), 486

5. Sausse L M. Microsyst Technol. 201319 (1), 1

6. Salonen J, Kaukonen A M, Hirvonen J. J Pharm Scie. 97 (2), 632 
7. Ololade O, Al-Qaffaf B and Bhusan D D. Transdermal drug delivery using microneedles. Oxford, UK, 2010, pp96-115.

8. Ochoa M, Mousoulis C, Ziaie B. Adv Drug Delivery Rev. 201264 (14), 1603

9. Donnelly R F, Majithiya R, Singh R T R, Desmond I. J. Morrow, Martin J. Garland, Yusuf K. Demir, Migalska K, Ryan E, Gillen D, Scott C J, and David A. Pharm Res. 201128 (1), 41

10. Van der Maaden K, Jiskoot W, Bouwstra J. Journal of Controlled Release. 2012161 (2), 645

11. Chen MC, Wang KW, Chen DH, Ling MH, Liu CY. Acta Biomater. 201513 (1), 344

12. Yang, S.Y. Nat. Commun. 4:1702

13. Yeu-Chun K, Park J H, and Prausnitz M R. Adv Drug Delivery Rev. 201264 (14), 1547

14. Escobar-Chávez J J, Bonilla-Martínez D, Angélica V G M, Molina T E, Casas A N, and Revilla-Vázquez A L. J Clinical Pharm. 2011 51, 964

15. Guohua L, Badkar A, Kalluri H, Banga A K. J Pharmaceutical Scie. 201099 (4), 1931

16. Verhoeven, M.L.P.M and Bystrova, S.N. Microelectronic engineering. 2012 98, 659 